\title{
Diamond crystallization in carbonate-silicate systems: implications for natural diamond genesis
}

\author{
A. Shatskiy ${ }^{1}$, Yu.M. Borzdov ${ }^{2}$, A.G. Sokol ${ }^{2}$, T. Katsura ${ }^{1}$ and Yu.N. Pal'yanov ${ }^{2}$ \\ ${ }^{1}$ Institute for Study of the Earth.s Interior, Okayama University, Misasa, Tottori, Japan \\ ${ }^{2}$ Institute of Geology and Mineralogy, Siberian Branch of the Russian Academy of Sciences, Koptyug Pr., \\ 3, Novosibirsk, Russian Federation
}

The abundance of inclusions in diamonds implies that the base of the mantle diamond-forming medium was made up of sulfides, silicates, and oxides. Findings of fluid inclusions in diamonds from kimberlite pipes suggest that a very important feature of the mantle medium of diamond crystallization was its enrichment in potassium and carbonates (Schrauder \& Navon 1994). According to experimental data only alkaline carbonate melts and $\mathrm{C}-\mathrm{O}-\mathrm{H}$ fluid can provide the diamond crystallization at the $\mathrm{P}-\mathrm{T}$ conditions corresponding to the formation of natural diamonds (Pal'yanov et al., 2002). Since the major constituent of the Earth's mantle is silicates, the experimental study of diamond crystallization in potassium bearing carbonate-silicate systems is essential for understanding the natural diamond formation.

Diamond crystallization and character of phase formation in the systems $\mathrm{K}_{2} \mathrm{CO}_{3}-\mathrm{C}, \mathrm{K}_{2} \mathrm{CO}_{3}-\mathrm{SiO}_{2}-\mathrm{C}$, and $\mathrm{K}_{2} \mathrm{CO}_{3}-\mathrm{Mg}_{2} \mathrm{SiO}_{4}-\mathrm{C}$ were studied at $6.3 \mathrm{GPa}$ and $1650{ }^{\circ} \mathrm{C}$ for 40 hours, using a Malinovskiy-type (8-6) milti-anvil apparatus (BARS) installed in the Institute of Geology and Mineralogy at Novosibirsk. The $\mathrm{SiO}_{2} / \mathrm{K}_{2} \mathrm{CO}_{3}$ and $\mathrm{Mg}_{2} \mathrm{SiO}_{4} / \mathrm{K}_{2} \mathrm{CO}_{3}$ ratios were chosen as variable parameters. The degree of graphite-todiamond transformation and rate of diamond growth on seeds have been determined as a function of these ratios.

The character of phase formation as a function of $\mathrm{SiO}_{2} / \mathrm{K}_{2} \mathrm{CO}_{3}$ is schematically shown in Fig. 1a. As $\mathrm{SiO}_{2}$ increases in the system, the carbonate-silicate melt loses its capacity to initiate diamond nucleation and, in the domain of high concentrations of $\mathrm{SiO}_{2}$, provides only recrystallization of metastable graphite and diamond growth on seeds. As the melt becomes richer in silica, first $\mathrm{K}$-wadeite $\left(\mathrm{K}_{2} \mathrm{SiSi}_{3} \mathrm{O}_{9}\right)$ and then coesite crystallize.

The character of phase formation and diamond crystallization with different $\mathrm{K}_{2} \mathrm{CO}_{3} / \mathrm{Mg}_{2} \mathrm{SiO}_{4}$ ratios is shown in Fig. 1b. It is seen that as the $\mathrm{Mg}_{2} \mathrm{SiO}_{4}$ content increases, the carbonate-silicate melt ceases to provide spontaneous nucleation of diamond, and in the domain of high concentrations of $\mathrm{Mg}_{2} \mathrm{SiO}_{4}$, only seeded diamond growth and recrystallization of metastable graphite are possible. Simultaneously, the carbonate- silicate melt becomes oversaturated first with forsterite and then, with forsterite and periclase.
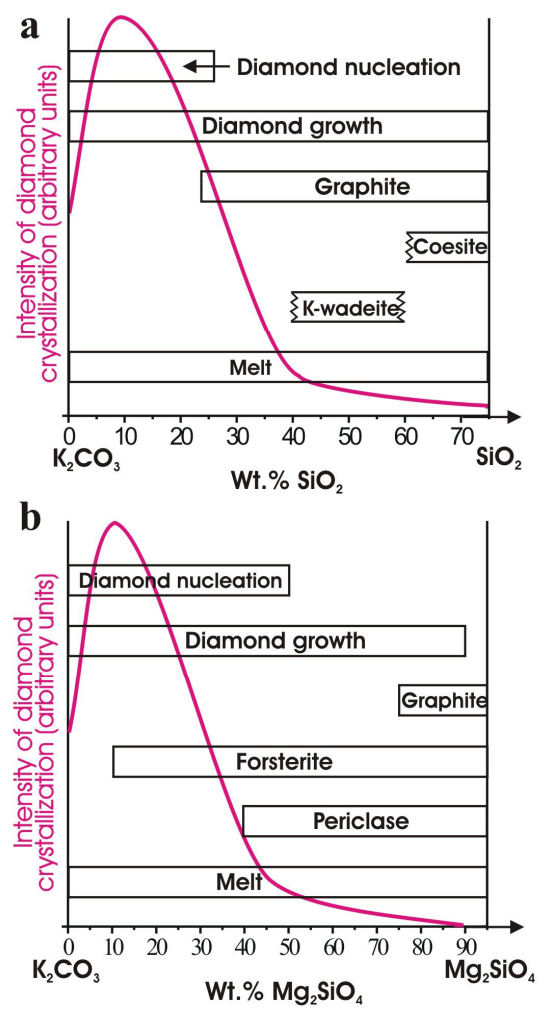

Fig. 1. Character of phase formation and diamond crystallization in the system $\mathrm{K}_{2} \mathrm{CO}_{3}-\mathrm{SiO}_{2}-\mathrm{C}$ (a) and $\mathrm{K}_{2} \mathrm{CO}_{3}-\mathrm{Mg}_{2} \mathrm{SiO}_{4}-\mathrm{C}$ (b) at $6.3 \mathrm{GPa}, 1650{ }^{\circ} \mathrm{C}$ and run duration of $40 \mathrm{hs}$.

The geochemical and petrological data available indicate that the crystallization, at least, of some part of diamonds is related to processes of mantle metasomatism and occurred from the carbonoversaturated carbonate-silicate fluxes. According to experimental data, carbonate melts could have been formed under the conditions of the upper mantle as a result of partial melting of carbonatized mantle peridotite near its solidus. An increase in temperature 
by $70-100{ }^{\circ} \mathrm{C}$ above the solidus could led to a considerable increase in silicate/carbonate ratio and gradual transition from carbonate to carbonate-silicate melt compositionally close to kimberlite (Dalton \& Presnall, 1998)

To estimate the effect of the silicate/carbonate ratio on the diamond formation in the studied systems, we determined the degree of graphite-to-diamond transformation as: $\boldsymbol{A}=\left(\mathrm{M}_{\mathrm{Dm}} / \mathrm{M}_{\mathrm{Gr}}\right) 100 \%$, where $\mathrm{M}_{\mathrm{Dm}}$ is the mass of the obtained diamond except of the diamond layers grown on the seed crystals, $\mathrm{M}_{\mathrm{Gr}}$ is the mass of the initial graphite. The results show that as the $\mathrm{SiO}_{2}$ content in the system $\mathrm{K}_{2} \mathrm{CO}_{3}-\mathrm{SiO}_{2}-\mathrm{C}$ increases to 10 wt. $\%, \boldsymbol{A}$ increases by $50 \%$ and then, with a further increase in silica concentration, successively decreases to zero (Fig. 2). The dependence of the degree of graphite-to-diamond transformation on the $\mathrm{Mg}_{2} \mathrm{SiO}_{4}$ content in the system $\mathrm{K}_{2} \mathrm{CO}_{3}-\mathrm{Mg}_{2} \mathrm{SiO}_{4}-\mathrm{C}$ is similar to the $\boldsymbol{A}$ dependence of $\mathrm{SiO}_{2}$ concentration in the system $\mathrm{K}_{2} \mathrm{CO}_{3}-\mathrm{SiO}_{2}-\mathrm{C}$ (Fig. 2). In the domain of high concentrations of silica and forsterite, the intensity of diamond formation was estimated from the rate of diamond seeded growth. The results of measurements given in Fig. 3 indicate a gradual decrease in diamond growth rate on the faces $\{100\}$ and $\{111\}$ of seed crystals with increasing content of silica in the system $\mathrm{K}_{2} \mathrm{CO}_{3}-\mathrm{SiO}_{2}-\mathrm{C}$ and forsterite in the system $\mathrm{K}_{2} \mathrm{CO}_{3}-$ $\mathrm{Mg}_{2} \mathrm{SiO}_{4}-\mathrm{C}$ (Fig. 3). Thus, the general tendency is that the catalytic potential of the studied systems relative to diamond varies with an increase in silicate/carbonate ratio, increasing in the domain of low concentrations of silicate and decreasing in the domain of its high concentrations (Fig. 1).

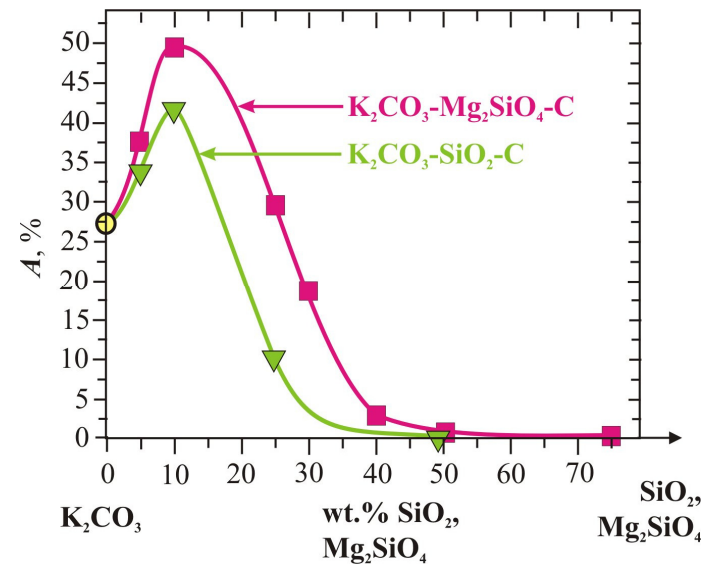

Fig. 2. Degree of graphite-to-diamond transformation (A) as a function of $\mathrm{SiO}_{2}$ concentration in the system $\mathrm{K}_{2} \mathrm{CO}_{3}-\mathrm{SiO}_{2}-\mathrm{C}$ and $\mathrm{Mg}_{2} \mathrm{SiO}_{4}$ in the system $\mathrm{K}_{2} \mathrm{CO}_{3}-$ $\mathrm{Mg}_{2} \mathrm{SiO}_{4}-\mathrm{C}$.
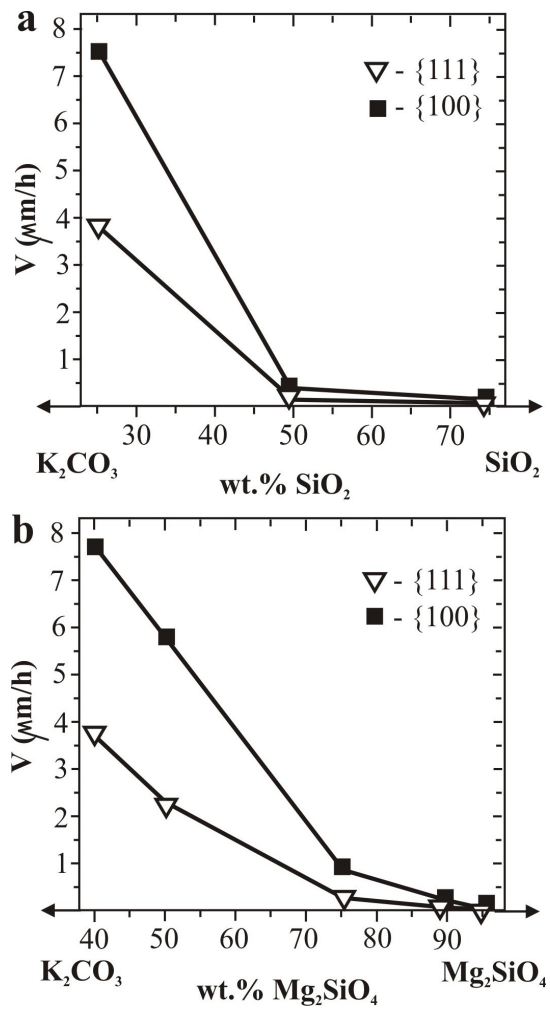

Fig. 3. Rate of diamond crystal growth on the seed versus $\mathrm{SiO}_{2}$ and $\mathrm{Mg}_{2} \mathrm{SiO}_{4}$ content in the system $\mathrm{K}_{2} \mathrm{CO}_{3}-$ $\mathrm{SiO}_{2}-\mathrm{C}$ (a) and $\mathrm{K}_{2} \mathrm{CO}_{3}-\mathrm{Mg}_{2} \mathrm{SiO}_{4}-\mathrm{C}(\mathrm{b})$, respectively.

In the range of compositions from 5 to $25 \mathrm{wt} . \% \mathrm{SiO}_{2}$ in the system $\mathrm{K}_{2} \mathrm{CO}_{3}-\mathrm{SiO}_{2}-\mathrm{C}$, silica was completely dissolved in the carbonate melt (Fig. 1). Therefore, an increase in $\mathrm{SiO}_{2}$ concentration in the system was accompanied with the same increase in its concentration in the melt. At $50 \mathrm{wt} . \% \mathrm{SiO}_{2}$, the system becomes oversaturated with $\mathrm{K}$-wadeite, and at 75 wt.\%, with coesite (Fig. 1). On the basis of these data, the solubility of $\mathrm{SiO}_{2}$ in the $\mathrm{K}_{2} \mathrm{CO}_{3}$ melt at $6.3 \mathrm{GPa}$ and $1650{ }^{\circ} \mathrm{C}$ is estimated at $\geq 25$ wt. $\%$. The principal structural differences of the carbonate and silicate melt suggest that the $\mathrm{SiO}_{2}$ dissolution in the carbonate melt should be accompanied by an increased degree of its polymerization and viscosity (Treiman \& Schedl 1983). Given these estimates and experimental data, the change in intensity of diamond formation in the system $\mathrm{K}_{2} \mathrm{CO}_{3}-\mathrm{SiO}_{2}-\mathrm{C}$ is most likely due to considerable changes in the structure and properties of carbonate-silicate melt with increasing concentration of $\mathrm{SiO}_{2}$ dissolved in it. Since the dependence of the catalytic potential on $\mathrm{SiO}_{2} / \mathrm{K}_{2} \mathrm{CO}_{3}$ and $\mathrm{Mg}_{2} \mathrm{SiO}_{4} / \mathrm{K}_{2} \mathrm{CO}_{3}$ in the system are similar, the change in intensity of diamond crystallization with an increased content of $\mathrm{Mg}_{2} \mathrm{SiO}_{4}$ in the system $\mathrm{K}_{2} \mathrm{CO}_{3}-\mathrm{Mg}_{2} \mathrm{SiO}_{4}-\mathrm{C}$ is possibly related to the increased silica-to-carbonate ratio in the melt.

The crystallization of metastable graphite (Fig. 4) as well as termination of diamond crystallization in the domain of high concentrations of $\mathrm{SiO}_{2}$ or $\mathrm{Mg}_{2} \mathrm{SiO}_{4}$ (Fig. 1) are probably related to the fundamental 
changes of structural properties of the carbonatesilicate melt, which favor the crystallization of carbon in $\mathrm{sp} 2$ and $\mathrm{sp} 3$ forms at high and low silicate concentration, respectively.
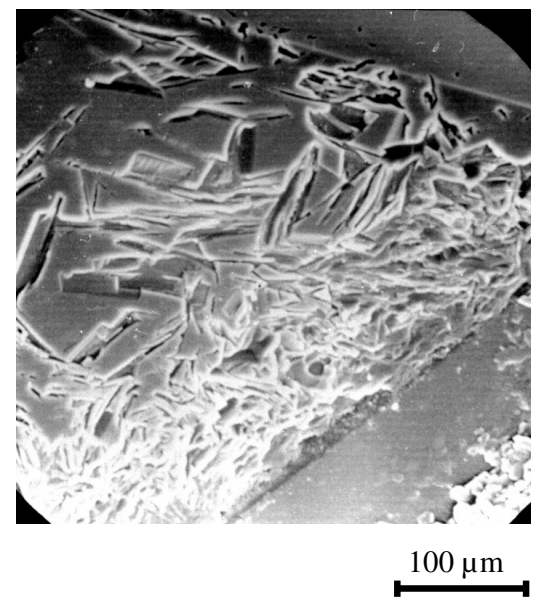

Fig. 4. Prints of joint diamond-graphite growth on the $\{111\}$ face of the seed at $75 \mathrm{wt} \% \mathrm{Mg}_{2} \mathrm{SiO}_{4}$ in the system $\mathrm{K}_{2} \mathrm{CO}_{3}-\mathrm{Mg}_{2} \mathrm{SiO}_{4}-\mathrm{C}$.
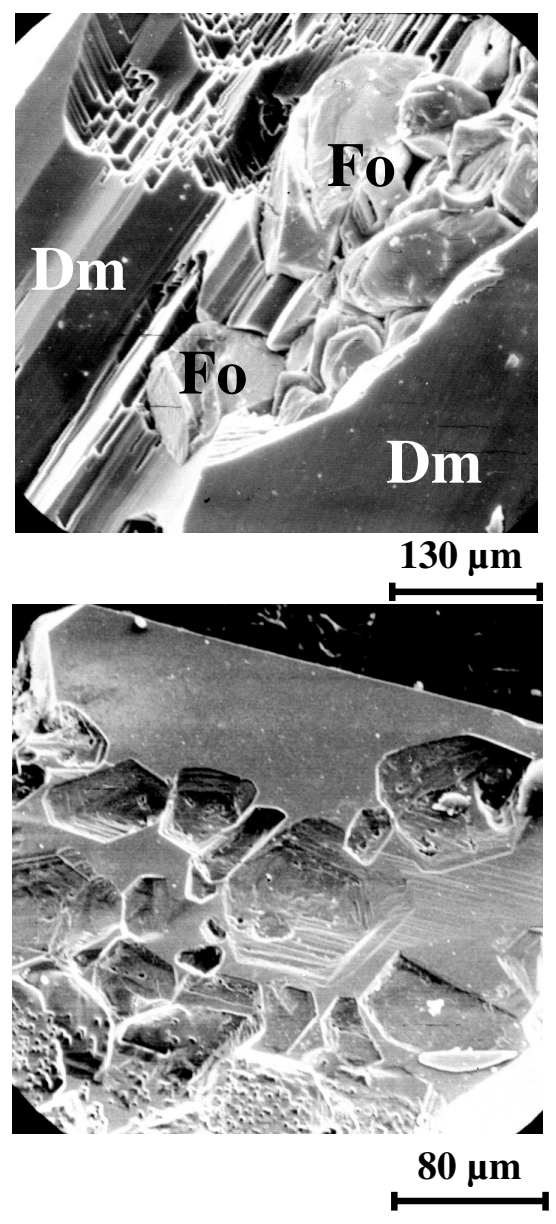

Fig. 5. Illustration of cocrystallization of diamond and forsterite: a) fragment of diamond seed crystal with ingrown forsterite crystals at 40 wt $\% \mathrm{Mg}_{2} \mathrm{SiO}_{4} ;$ b) induction susrfaces of diamond-forsterite cogrowth on $\{111\}$ face of seed crystal at $30 \mathrm{wt} \% \mathrm{Mg}_{2} \mathrm{SiO}_{4}$.

In solving many problems related to diamond genesis, of special importance is the study of the effect of physicochemical conditions of growth on crystal morphology. It has been established in (Pal'yanov et al. 1999) that in the alkaline carbonate-carbon systems at 7.0 GPa and $1700-1750{ }^{\circ} \mathrm{C}$ the diamond morphology is well determined by the cationic composition of carbonates and gradually changes from cuboctahedron to octahedron in the series $\mathrm{Li}_{2} \mathrm{CO}_{3}-\mathrm{Na}_{2} \mathrm{CO}_{3}-$ $\mathrm{K}_{2} \mathrm{CO}_{3}-\mathrm{Cs}_{2} \mathrm{CO}_{3}$. The results of our studies show that under the constant cationic composition of alkaline carbonate, the introduction of silica or forsterite into the system $\mathrm{K}_{2} \mathrm{CO}_{3}-\mathrm{C}$ does not change the diamond morphology (Shatskii et al. 2002). It is probable that in alkaline carbonate and carbonate-silicate systems the carbonate composition is one of the main factors controlling the diamond morphology.

The cooccurrence of ultrapotassic fluxes and minerals of the main mantle-derived parageneses in inclusions in natural diamonds implies that these melts played an important role in crystallization of diamonds of eclogitic and peridotitic mantle parageneses. In the present work, we succeeded in reproducing the conditions under which diamond was crystallized from a potassium carbonate-silicate melt including the main components of mantle ultrapotassic fluxes, together with coesite (mineral of eclogite paragenesis) in the $\mathrm{K}_{2} \mathrm{CO}_{3}-\mathrm{SiO}_{2}-\mathrm{C}$ system and with forsterite (mineral of peridotite paragenesis) in the system $\mathrm{K}_{2} \mathrm{CO}_{3}-\mathrm{Mg}_{2} \mathrm{SiO}_{4}$ C (Fig. 5).

Schrauder, M., and Navon, O. 1994, Hydrous and carbonatitic mantle fluids in fibrous diamonds from Jwaneng, Botswana, Geochim. Cosmochim. Acta, 58, 2, 761-771.

Pal'yanov, Yu.N., Sokol, A.G., Borzdov, Yu.M., and Khokhryakov, A.F., 2002, Fluid-bearing alkaline carbonate melts as the medium for the formation of diamonds in the Earth's mantle: an experimental study, Lithos, 60, 145-159.

Dalton, J.A., and Presnall, D.C., 1998, The continuum of primary carbonatitic-kimberlitic melt compositions in equilibrium with lherzolite: data from the system $\mathrm{CaO}-\mathrm{MgO}-\mathrm{Al}_{2} \mathrm{O}_{3}-\mathrm{SiO}_{2}-\mathrm{CO}_{2}$ at 6 GPa, J. Petrology, 39, 11-12, 1953-1964.

Treiman, A.H., and Schedl, A., 1983, Properties of carbonatite magma and processes in carbonatite magma chambers, J. Geology, 91, 437-447.

Pal'yanov, Yu.N., Sokol, A.G., Borzdov, Yu.M., Khokhriakov, A.F., Shatsky, A.F., and Sobolev, N.V., 1999, The diamond growth from $\mathrm{Li}_{2} \mathrm{CO}_{3}$, $\mathrm{Na}_{2} \mathrm{CO}_{3}, \mathrm{~K}_{2} \mathrm{CO}_{3}$ and $\mathrm{Cs}_{2} \mathrm{CO}_{3}$ solvent-catalysts at $\mathrm{P}$ $=7 \mathrm{GPa}$ and $\mathrm{T}=1700-1750{ }^{\circ} \mathrm{C}$, Diam. Relat. Mater., 8, 1118-1124.

Shatsky, A.F., Borzdov, Yu.M., Sokol, A.G. and Pal'yanov, Yu.N., 2002, Phase formation and diamond crystallization in carbon-bearing ultrapotassic carbonate-silicate systems, Russian Geology and Geophysics 43, 940-950. 